\title{
A Case of Refractory Esophageal Ulcer Caused by Radiotherapy for Hepatocellular Carcinoma
}

\author{
Kazu Hamada ${ }^{\mathrm{a}, \mathrm{b}}$, Tohru Itoh $^{\mathrm{b}}$, Ken Kawaura ${ }^{\mathrm{b}}$, Hiroaki Kuno ${ }^{\mathrm{b}}$, Junji Kamai ${ }^{\mathrm{b}}$, Rika Kobayasi ${ }^{\mathrm{b}}$, \\ Sadahumi Azukisawa $^{\mathrm{b}}$, Hidekazu Kitakata ${ }^{\mathrm{b}}$, Taishi Ishisaka ${ }^{\mathrm{a}}$, Yuta Igarashi ${ }^{\mathrm{a}}$, Kumie Kodera ${ }^{\mathrm{a}}$, \\ Tazuo Okuno ${ }^{a}$, Takuro Morita ${ }^{\mathrm{a}}$, Tarou Himeno ${ }^{\mathrm{a}}$, Hiroshi Yano ${ }^{\mathrm{a}}$, Toshihiro Higashikawa ${ }^{\mathrm{a}}$, \\ Osamu Iritani ${ }^{\mathrm{a}}$, Kunimitsu Iwai ${ }^{\mathrm{a}}$, Shigeto Morimoto ${ }^{\mathrm{a}}$, Munetaka Matoba ${ }^{\mathrm{c}}$, \\ Masashi Okuro ${ }^{a}$,
}

\begin{abstract}
A 77-year-old man who underwent radiotherapy for hepatocellular carcinoma 6 months prior consulted for esophageal obstruction. Esophagogastroduodenoscopy revealed an esophageal ulcer caused by radiotherapy for hepatocellular carcinoma. He was treated with dietary counseling and vonoprazan. After 9 months, the ulcer improved but a moderate stenosis remained. Several factors such as high fraction size, history of chemotherapy, and stress associated with food intake might involve in the development of a radiation-associated ulcer. Opportunities to choose radiotherapy for hepatocellular carcinoma may increase, so we hypothesize that esophageal ulcers might be a complication that should be noted associated with this therapy.
\end{abstract}

Keywords: Chronic esophageal toxicity; Esophageal ulcer; Esophageal stenosis; Hepatocellular carcinoma; Radiotherapy

\section{Introduction}

Hepatectomy, radiofrequency ablation, transcatheter arterial chemoembolization (TACE), molecularly-targeted therapy, and liver transplantation are conventional treatments for hepatocellular carcinoma (HCC). In addition, radiotherapy is often performed for HCC in the case where it is difficult to perform those treatments [1]. Radiotherapy was rarely performed for $\mathrm{HCC}$ in the past because it was difficult to avoid radiation ex-

Manuscript submitted March 8, 2021, accepted April 15, 2021

Published online May 14, 2021

aDepartment of Geriatric Medicine, Kanazawa Medical University, Ishikawa, Japan

bDepartment of Gastroenterological Endoscopy, Kanazawa Medical University, Ishikawa, Japan

'Department of Radiology, Kanazawa Medical University, Ishikawa, Japan

${ }^{\mathrm{d} C}$ Corresponding Author: Masashi Okuro, Department of Geriatric Medicine, Kanazawa Medical University, Uchinada, Kahoku-gun, Ishikawa 920-0293, Japan. Email: okuro@kanazawa-med.ac.jp

doi: https://doi.org/10.14740/wjon1370 posure to the normal hepatocyte. However, stereotactic body radiotherapy (SBRT) and intensity-modulated radiotherapy (IMRT) made it possible to perform radiotherapy for HCC without excessive radiation exposure to the normal hepatocyte in late years. It is presumed that the number of HCC cases treated with radiotherapy will increase in the future. Because of this, we need to be careful about the complications that we did not experience so far. What we report here is a case of refractory esophageal ulcer caused by radiotherapy for HCC.

\section{Case Report}

A 77-year-old man was admitted with chief complaints of loss of appetite and obstruction of epigastrium. His family history was not applicable. The medicines he used included vonoprazan $10 \mathrm{mg}$ /day, amlodipine $5 \mathrm{mg}$ /day, pilocarpine $5 \mathrm{mg}$ /day, and brotizolam $0.5 \mathrm{mg} /$ day. Past medical history showed that he had tongue cancer, HCC in hepatic segment 2, and gastric cancer at 76 years old. He received chemoradiotherapy (chemotherapy: tegafur-gimeracil-oteracil potassium, $100 \mathrm{mg} / \mathrm{day}$, administered 2 weeks on/ 1 week off, finished at two cycles because of grade 3 oral mucositis; radiotherapy: IMRT, the total dose: 70.0 Gy in 35 fractions to oropharynx) for tongue cancer, TACE for HCC, and endoscopic submucosal dissection for gastric cancer in the same year. There was no history of treatment of hepatitis, but it was presumed that he had subclinical hepatitis B (HB) in the past (HBsAg: -, HBsAb: +, HBeAg: -, HBeAb: -, HBcAb: +).

He had esophagogastroduodenoscopy (EGD) for a followup examination after endoscope treatment of gastric cancer at the beginning of December, 2017. There were no abnormal endoscopic findings on lower esophagus and cardia at this point (Fig. 1).

The size of HCC in hepatic segment 2 reduced after TACE. However, it recurred and grew up to $4 \mathrm{~cm}$ in size afterwards (Fig. 2a, b). His Eastern Cooperative Oncology Group (ECOG) performance status was grade 0, Child-Pugh score was class A. He was tried TACE for HCC once again, but it failed because the access to responsible vessel was difficult. He received radiotherapy for HCC (SBRT, radiation on alternate days, the total dose: 49.0 Gy in seven fractions (48.4 Gy 

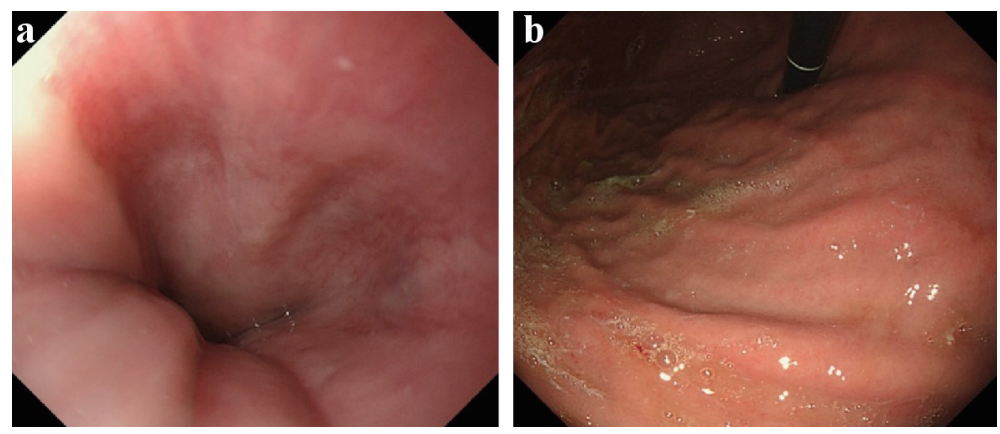

Figure 1. Esophagogastroduodenoscopy of December 2017, before radiotherapy. (a) Lower esophagus, $39 \mathrm{~cm}$ from the incisors. (b) Cardia of stomach. They were endoscopic findings of the area before performed radiotherapy for hepatocellular carcinoma (HCC). At this point, there were no inflammatory findings on the lower esophagus and the cardia of the stomach.
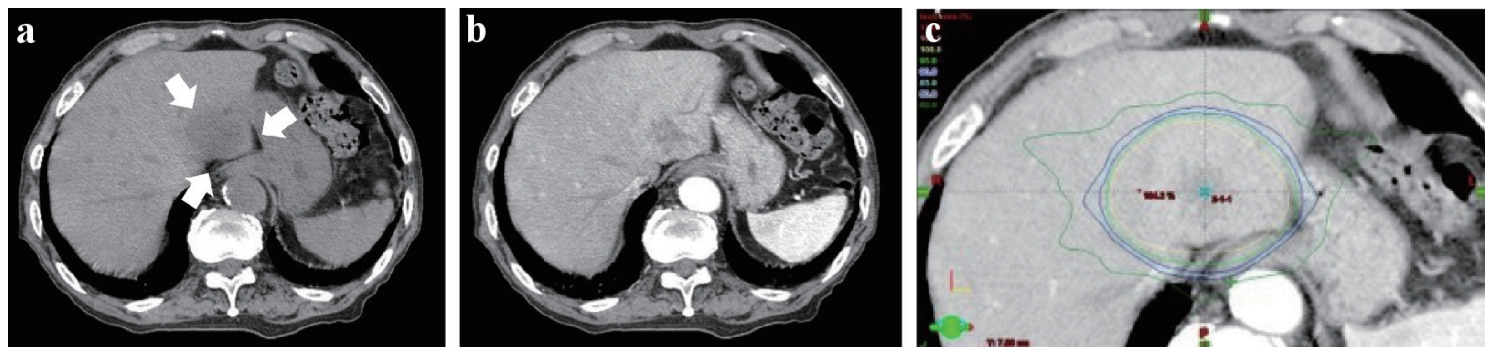

Figure 2. Abdominal computed tomography (CT) of December 2017, before radiotherapy. (a) Abdominal CT (plain). (b) Abdominal CT (contrast-enhanced; arterial phase). (c) Dose distribution (isodose distributions: yellow line 100\%; inside/green line 95\%; blue line 90\%). There was a low density area (about $4 \mathrm{~cm}$ in size; white arrow) in hepatic segment 2 for abdominal plain CT. It was well-enhanced in the arterial phase for contrast-enhanced CT. The lesion was close to the gastroesophageal junction. The lower esophagus and the cardia of the stomach were included in the range of the radiation (yellow arrow head). The total dose to $\mathrm{HCC}$ was D0.5 $\mathrm{cm}^{3}=49.0 \mathrm{~Gy}$, the lower esophagus: D0.5 $\mathrm{cm}^{3}=48.4 \mathrm{~Gy}$.

to the lower esophagus)) in the S2 segment from the beginning to the middle of December, 2017 (Fig. 2c). He did not have the symptom at the end of the radiotherapy. He did not visit our hospital for follow-up due to his self-judgment afterwards.

He consulted our hospital again in June 2018 because he gradually developed loss of appetite and obstruction in epigastrium after deglutition from around April. EGD revealed a semicircular esophageal ulcer with slight stenosis on the lower esophagus, $39 \mathrm{~cm}$ from the incisors (Fig. 3a), and localized gastritis with hematin on the cardia of the stomach (Fig. 3b). We diagnosed it as esophageal ulcer and gastritis, which were chronic side effect of radiotherapy for HCC because this area was included in the range of the radiation (Fig. 2c); and there was no inflammation in it before the radiotherapy. We performed biopsies of these lesions repeatedly, but the malignant findings were never seen. In addition, hyalinization of the capillary wall was seen in the biopsy segment of the esophageal lesion. They were pathologically consistent findings for the esophageal lesion caused by radiation.

He received conservative therapy which included dietary intervention, combination of tube feeding using gastrostoma, and administration of vonoprazan for these lesions; and he al-
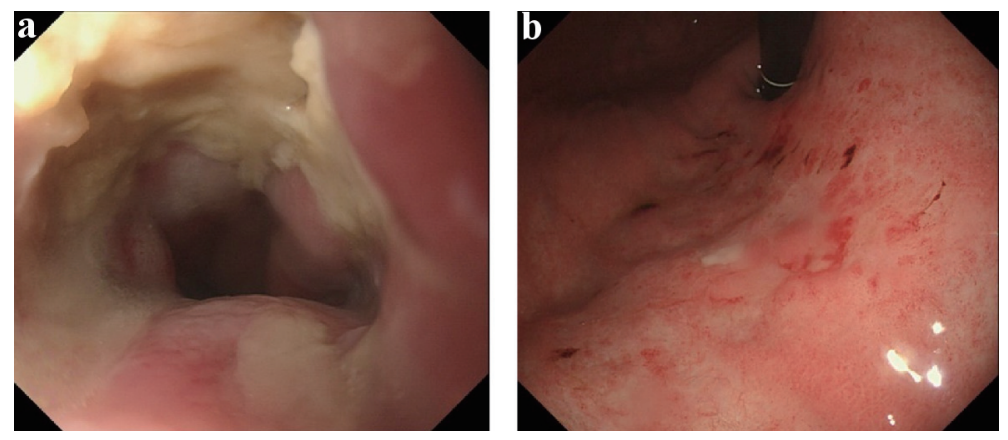

Figure 3. Esophagogastroduodenoscopy of June 2018, after radiotherapy. (a) Lower esophagus. (b) Cardia of stomach. There were semicircular esophageal ulcer with slight stenosis on the lower esophagus, $39 \mathrm{~cm}$ from the incisors, and localized gastritis with hematin on the cardia of the stomach. 


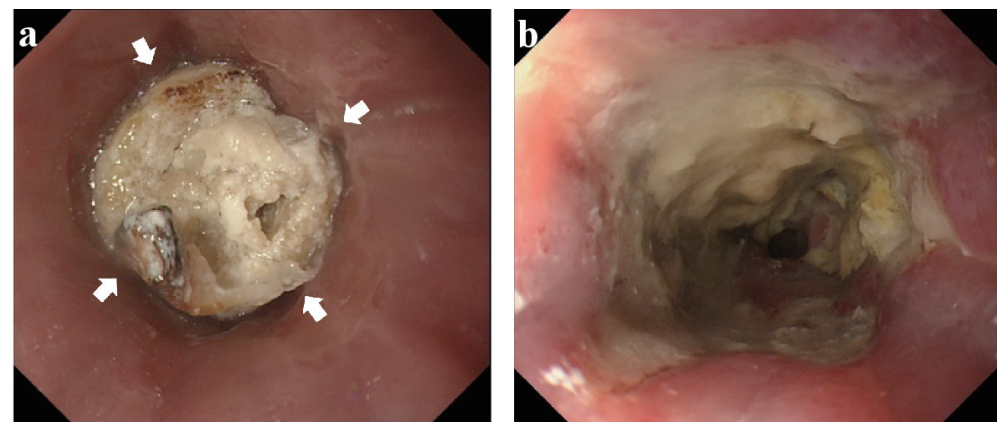

Figure 4. Esophagogastroduodenoscopy of July 2018, after radiotherapy. (a) Lower esophagus (before removal of foreign body). (b) Lower esophagus (after removal of it). Stagnated chicken was found in the lower esophagus (white arrow). After the removal, the range of the esophageal ulcer enlarged to the oral side.

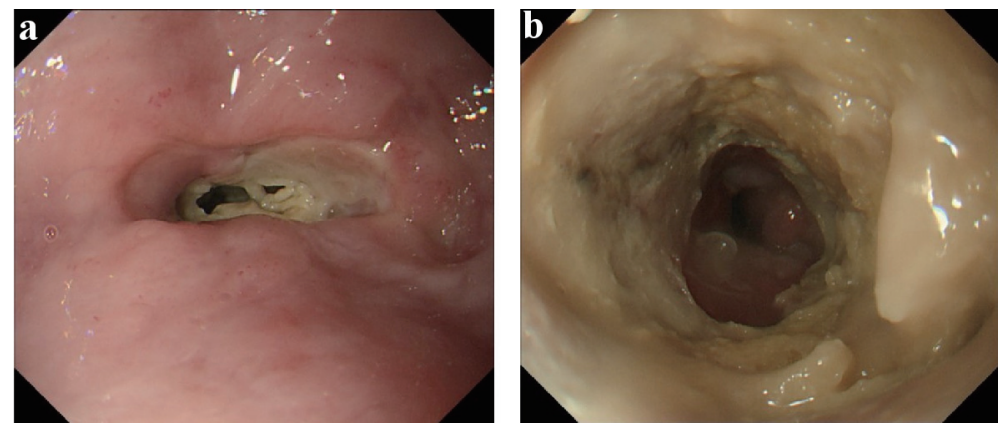

Figure 5. Esophagogastroduodenoscopy of August 2018. (a) Lower esophagus (before endoscope passed). (b) Lower esophagus (after it passed). Esophageal ulcer grew up for the circumferential lesion with the progression of stenosis. It was barely passed by GIF-H290 (8.9 mm (outer diameter); Olympus Medical Systems Corp., Japan).

ready had gastrostoma which was done as part of chemoradiotherapy for tongue cancer before. However, he was not able to continue dietary intervention. He visited our hospital in July 2018 because of vomiting after eating barbecued chicken without sufficient amount of chewing. Stagnated food and chicken was found in the lower esophagus by EGD on the same day (Fig. 4a). We performed removal of foreign body by EGD immediately. After the EGD, the area of the esophageal ulcer enlarged to the oral side (Fig. 4b). He received conservative therapy since he did not have achalasia again; however, it grew up to a circumferential ulcer with progression of stenosis which
GIF-H290 (8.9 mm outer diameter; Olympus Medical Systems Corp., Japan) barely passed in August 2018 (Fig. 5). The localized gastritis on the cardia improved with capillary ectasia.

We inferred that it was difficult to improve the esophageal ulcer/stenosis with conservative therapy and this lesion had the risk to cause esophageal obstruction/ perforation. We discussed the endoscopic balloon dilation or surgery with him, but he chose to continue conservative therapy.

The esophageal ulcer improved slowly by conservative therapy. It almost healed with moderate stenosis in March 2019 (Fig. 6). The symptom/dysphagia score [2] was gradu-
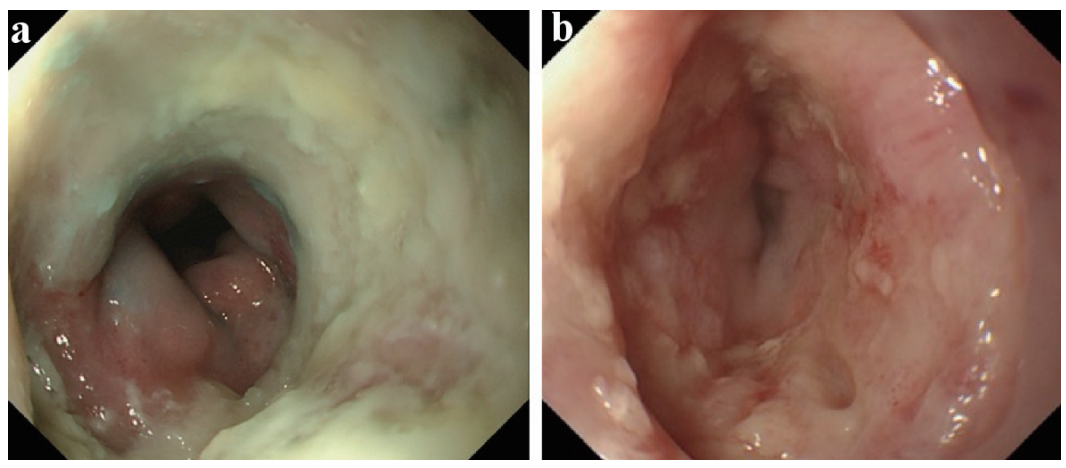

Figure 6. Esophagogastroduodenoscopy of September 2018 and March 2019. (a) Lower esophagus (September 2018). (b) Lower esophagus (March 2019). The esophageal ulcer was slowly improved by conservative therapy. It almost healed with moderate stenosis in March 2019. 


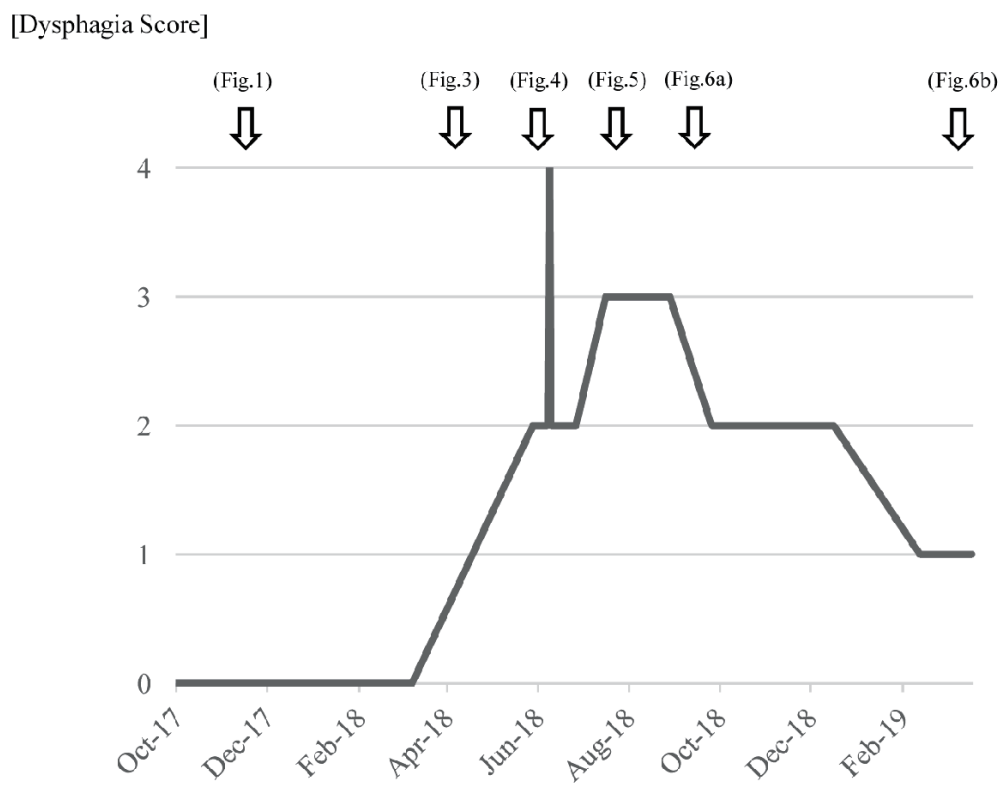

Figure 7. Changes in dysphagia score at different times. Dysphagia score: 4 = no passage (unable to swallow anything); $3=$ very poor passage (able to swallow liquids only); 2 = poor passage (able to eat semi-solid foods); 1 = moderate passage (able to eat some solid foods); 0 = no dysphagia (able to eat normal diet).

ally improved and became stable (Fig. 7).

\section{Discussion}

The radiation esophageal toxicity is classified in acute type and chronic type. Most acute type cases are radiation esophagitis. It occurs about 2 - 3 weeks after performing radiotherapy and disappears after stopping the treatment. Chronic type occurs more than 3 months later after performing radiotherapy and often causes irreversible stenosis [3,4]. The patient received SBRT for a large HCC lesion in the lower esophagus. It was a situation where the high-dose radiation to the esophagus could have occurred because the range of the radiation was set slightly wider from HCC. He had a symptom more than 4 months after the radiotherapy and the esophageal ulcer was refractory. Therefore, we thought that the case was chronic esophageal/ gastric toxicity caused by radiotherapy.

The total dose of radiation is set to 60 - 70 Gy when radiotherapy is performed to esophageal cancer [5]. The esophageal ulcer is often caused by intracavity-external radiotherapy for esophageal cancer $[6,7]$. It is healed by conservative therapy $[7,8]$, but the severe intractable ulcer with the perforation may occurs [9]. The esophageal stenosis and the bronchus ulcer are rarely caused by external radiotherapy, but the esophageal ulcer does not occur from the therapy $[10,11]$. The tolerance dose of the esophagus is usually about 55 Gy [12]. We had though that it was not likely to cause esophageal ulcer by radiotherapy because the total dose of radiation he received was 49 Gy for HCC and 48.4 Gy to the lower esophagus. However, the fraction size was set to 7 Gy in this case although it was common that a fraction size to the esophagus was set to around 2 Gy. For the intracavity radiotherapy, the fraction size is cor- related with occurrence of esophageal ulcer more than the total dose $[10,13]$. In this case, there is a high possibility that esophageal ulcer was caused by radiotherapy for HCC. The treatment target was in the hepatic vessels, and the esophagus of this case was irradiated with the dose of $31.2 \mathrm{~Gy}$ in four fractions [14]. It was thought that the esophageal ulcer was caused by radiotherapy for $\mathrm{HCC}$ in this case because a fraction size was high-dose.

Low-dose of radiation is easy to cause the esophageal ulcer/stenosis in the patient performed chemoradiotherapy even if chemotherapy and radiotherapy are heterochrony [15-17]. The combination of SBRT and vascular endothelial growth factor inhibitor (VEGFI) for HCC increases bowel toxicity [18]. The patient was not treated with a VEGFI, but he received chemoradiotherapy with tegafur-gimeracil-oteracil potassium for tongue cancer. The previous systemic chemotherapy for tongue cancer might contribute to increasing radiosensitivity of local esophageal tissue.

In addition, it was thought that the physical stimulation stagnate food might contribute to the aggravation of the esophageal ulcer/stenosis.

In other words, we thought that the severe esophageal ulcer was caused and aggravated by some factors in this case are as follows: 1) radiation with high dose of a fraction size for HCC; 2) medical history of chemotherapy for tongue cancer; and 3) physical stimulation by food.

The endoscopic balloon dilation is one of the therapies for stenosis due to the radiation esophagitis $[19,20]$. However, endoscopic balloon dilatation is less effective for the esophageal stenosis caused by non-surgery [20]. Since he had the severe intractable ulcer caused by radiotherapy, he might not have gotten enough effect for the esophageal stenosis even if he received endoscopic balloon dilation. Hisakura et al proposed that surgi- 
cal therapy should be examined for the patient with the chronic esophageal ulcer after proton beam therapy because it could cause esophageal perforation [21]. Moreover, there is a report of the perforation case caused by the radiation esophagitis [9]. Therefore, we examined surgery for the improvement of stenosis and the prevention of the perforation. However, it was difficult to recommend it positively because he did not desire it and had many risks, such as old age, treatment history o for multiple cancers, and the influence of the radiotherapy.

There are few cases which had esophageal ulcer/stenosis caused by radiotherapy for non-esophageal cancer, such as lung cancer [3, 19, 22], laryngopharynx cancer [19, 23, 24], malignant lymphoma [15], and bone metastases of breast cancer [16]. Gastroduodenal ulcer and gastritis often occur as a complication of the radiotherapy for $\operatorname{HCC}[25,26]$. However, there are few reports describing that the esophageal ulcer/stenosis was caused by radiotherapy or proton beam therapy for $\mathrm{HCC}[14,27,28]$. It may be the rare case which was caused by chronic radiation esophageal toxicity with ulcer/stenosis for the HCC at this time. The number of radiotherapy for HCC may increase due to the development of its technology; and we think that chronic radiation esophageal toxicity will be one of the complications for HCC that should be noted. For combination of radiotherapy and sorafenib, a conventional fraction size ranging from 2.0 to 2.5 Gy may reduce the onset rate of bowel complications [29]. The cases which have history of chemotherapy without sorafenib may receive the similar effect by it, too. Moreover, it is necessary to minimize a dose of radiation for the esophagus in IMRT or employ a conventional fraction size when radiotherapy for HCC is performed in the cases with history of chemotherapy, or include the normal digestive tract in the range of the radiation.

\section{Conclusions}

We report here a case of refractory esophageal ulcer/stenosis caused by radiotherapy for HCC. It was thought that the severe esophageal ulcer was caused in this case by some factors, such as radiation with high dose of a fraction size, medical history of chemotherapy, and physical stimulation to the esophagus. There were few cases similar to this, but the number of cases in which radiotherapy for HCC is performed may increase due to the development of radiotherapy. Therefore, we think that chronic radiation esophageal toxicity including ulcer/stenosis will be one of the complications for HCC that should be noted.

\section{Acknowledgments}

We thank all the investigators, staff and participants who participated in this report, for helpful discussions during manuscript development.

\section{Financial Disclosure}

None to declare.

\section{Conflict of Interest}

The authors declare no conflict of interest.

\section{Informed Consent}

Not applicable.

\section{Author Contributions}

Kazu Hamada wrote the manuscript; Masashi Okuro and Ken Kawaura collected data for review; all authors read and approved the final version of the manuscript.

\section{Data Availability}

The authors declare that data supporting the findings of this report are available within the article.

\section{References}

1. Omata M, Cheng AL, Kokudo N, Kudo M, Lee JM, Jia J, Tateishi R, et al. Asia-Pacific clinical practice guidelines on the management of hepatocellular carcinoma: a 2017 update. Hepatol Int. 2017;11(4):317-370.

2. Mellow MH, Pinkas H. Endoscopic laser therapy for malignancies affecting the esophagus and gastroesophageal junction. Analysis of technical and functional efficacy. Arch Intern Med. 1985;145(8):1443-1446.

3. Brindle JS, Shaw EG, Su JQ, Mailliard JA, Frank AR, Laurie JA, McLean M, et al. Pilot study of accelerated hyperfractionated thoracic radiation therapy in patients with unresectable stage III non-small cell lung carcinoma. Cancer. 1993;72(2):405-409.

4. Caglar HB, Othus M, Allen AM. Esophagus in-field: a new predictor for esophagitis. Radiother Oncol. 2010; 97(1):48-53.

5. Kitagawa Y, Uno T, Oyama T, Kato K, Kato H, Kawakubo $\mathrm{H}$, Kawamura O, et al. Esophageal cancer practice guidelines 2017 edited by the Japan esophageal society: part 2 . Esophagus. 2019;16(1):25-43.

6. Murakami Y, Nagata Y, Nishibuchi I, Kimura T, Kenjo M, Kaneyasu Y, Okabe T, et al. Long-term outcomes of intraluminal brachytherapy in combination with external beam radiotherapy for superficial esophageal cancer. Int J Clin Oncol. 2012;17(3):263-271.

7. Nishimura Y, Okuno Y, Ono K, Mitsumori M, Nagata Y, Hiraoka M. External beam radiation therapy with or without high-dose-rate intraluminal brachytherapy for patients with superficial esophageal carcinoma. Cancer. 1999;86(2):220-228.

8. Yang ZY, Hu YH, Gu XZ. Non-cancerous ulcer in the esophagus after radiotherapy for esophageal carcinoma-a report of 27 patients. Radiother Oncol. 1990;19(2):121- 
129.

9. Muijs CT, Beukema JC, Mul VE, Plukker JT, Sijtsema NM, Langendijk JA. External beam radiotherapy combined with intraluminal brachytherapy in esophageal carcinoma. Radiother Oncol. 2012;102(2):303-308.

10. Tonari A, Kusuda J, Nako Y, Maruyama Y, Ikeda I, Ikezaki H, Takayama M, et al. Evaluation of the effectiveness of radiation treatment methods for treatment of earlystage esophageal cancer. Journal of the Kyorin Medical Society. 2007;38(2+3):69-74.

11. Araujo CM, Souhami L, Gil RA, Carvalho R, Garcia JA, Froimtchuk MJ, Pinto LH, et al. A randomized trial comparing radiation therapy versus concomitant radiation therapy and chemotherapy in carcinoma of the thoracic esophagus. Cancer. 1991;67(9):2258-2261.

12. Emami B, Lyman J, Brown A, Coia L, Goitein M, Munzenrider JE, Shank B, et al. Tolerance of normal tissue to therapeutic irradiation. Int J Radiat Oncol Biol Phys. 1991;21(1):109-122.

13. Akagi Y, Hirokawa Y, Kagemoto M, Matsuura K, Ito A, Fujita K, Kenjo M, et al. Optimum fractionation for highdose-rate endoesophageal brachytherapy following external irradiation of early stage esophageal cancer. Int J Radiat Oncol Biol Phys. 1999;43(3):525-530.

14. Kato H, Yoshida H, Taniguch H, Nomura R, Sato K, Suzuki I, Nakata R. Cyberknife treatment for advanced or terminal stage hepatocellular carcinoma. World J Gastroenterol. 2015;21(46):13101-13112.

15. Yokoi K, Hosoda K, Katada N, Yamashita K, Moriya H, Mieno $\mathrm{H}$, Ohbu M, et al. Benign esophageal obstruction due to radiation esophagitis. Jpn J Gastroenterol Surg. 2017;50(6):419-428 (in Japanese).

16. Ichimura Y, Fukada I, Shibayama T, Miyamoto K, Kobayashi K, Kumai Y, Oguchi M, et al. A patient with breast cancer who developed radiation esophagitis after palliative irradiation of the lumbar vertebrae. Jpn J Breast Cancer. 2018;33(2):155-160.

17. Werner-Wasik M, Paulus R, Curran WJ, Jr., Byhardt R. Acute esophagitis and late lung toxicity in concurrent chemoradiotherapy trials in patients with locally advanced non-small-cell lung cancer: analysis of the radiation therapy oncology group (RTOG) database. Clin Lung Cancer. 2011;12(4):245-251.

18. Barney BM, Markovic SN, Laack NN, Miller RC, Sarkaria $\mathrm{JN}$, Macdonald $\mathrm{OK}$, Bauer $\mathrm{HJ}$, et al. Increased bowel toxicity in patients treated with a vascular endothelial growth factor inhibitor (VEGFI) after stereotactic body radiation therapy (SBRT). Int J Radiat Oncol Biol Phys. 2013;87(1):73-80.

19. Laurell G, Kraepelien T, Mavroidis P, Lind BK, Fernberg
JO, Beckman M, Lind MG. Stricture of the proximal esophagus in head and neck carcinoma patients after radiotherapy. Cancer. 2003;97(7):1693-1700.

20. Yoda Y, Yano T, Kaneko K, Tsuruta S, Oono Y, Kojima T, Minashi K, et al. Endoscopic balloon dilatation for benign fibrotic strictures after curative nonsurgical treatment for esophageal cancer. Surg Endosc. 2012;26(10):28772883.

21. Hisakura K, Terashima H, Nagai K, Kohno K, Tadano S, Enomoto T, Inagawa $\mathrm{S}$, et al. Clinical features of refractory radiation esophageal ulcer after proton beam therapy and its management in a patient with esophageal cancer. Jpn J Gastroenterol Surg. 2012;45(12):1145-1152 (in Japanese).

22. Sarna L, Swann S, Langer C, Werner-Wasik M, Nicolaou $\mathrm{N}$, Komaki R, Machtay M, et al. Clinically meaningful differences in patient-reported outcomes with amifostine in combination with chemoradiation for locally advanced non-small-cell lung cancer: an analysis of RTOG 9801. Int J Radiat Oncol Biol Phys. 2008;72(5):1378-1384.

23. Varghese BT, Paul S, Elizabeth MI, Somanathan T, Elizabeth KA. Late post radiation laryngeal chondronecrosis with pharyngooesophageal fibrosis. Indian J Cancer. 2004;41(2):81-84.

24. Maruyama Y, Arai K, Hoshida S, Yoneda K, Furukawa M, Yoshizaki T. Case of three delayed complications of radiotherapy: bilateral vocal cord immobility, esophageal obstruction and ruptured pseudoaneurysm of carotid artery. Auris Nasus Larynx. 2009;36(4):505-508.

25. Hawkins MA, Dawson LA. Radiation therapy for hepatocellular carcinoma: from palliation to cure. Cancer. 2006;106(8):1653-1663.

26. Kang JK, Kim MS, Cho CK, Yang KM, Yoo HJ, Kim $\mathrm{JH}, \mathrm{Bae} \mathrm{SH}$, et al. Stereotactic body radiation therapy for inoperable hepatocellular carcinoma as a local salvage treatment after incomplete transarterial chemoembolization. Cancer. 2012;118(21):5424-5431.

27. Jang WI, Bae SH, Kim MS, Han CJ, Park SC, Kim SB, Cho EH, et al. A phase 2 multicenter study of stereotactic body radiotherapy for hepatocellular carcinoma: Safety and efficacy. Cancer. 2020;126(2):363-372.

28. Higaki E, Fukaya M, Miyata K, Kawai R, Abe T. Successful two-stage operation for esophageal necrosis due to proton beam therapy followed by sorafenib in a case of large hepatocellular carcinoma. Surg Case Rep. 2020;6(1):138.

29. Chen SW, Lin LC, Kuo YC, Liang JA, Kuo CC, Chiou JF. Phase 2 study of combined sorafenib and radiation therapy in patients with advanced hepatocellular carcinoma. Int J Radiat Oncol Biol Phys. 2014;88(5):1041-1047. 